ARTICLE

https://doi.org/10.1038/s41467-021-22658-3

\title{
OPEN
}

\section{Kinetic resolution of indolines by asymmetric hydroxylamine formation}

\author{
Gang Wang ${ }^{1}$, Ran Lu², Chuangchuang $\mathrm{He}^{2}$ \& Lei Liu (1) ${ }^{1,2 \bowtie}$
}

Catalytic kinetic resolution of amines represents a longstanding challenge in chemical synthesis. Here, we described a kinetic resolution of secondary amines through oxygenation to produce enantiopure hydroxylamines involving $\mathrm{N}-\mathrm{O}$ bond formation. The economic and practical titanium-catalyzed asymmetric oxygenation with environmentally benign hydrogen peroxide as oxidant is applicable to a range of racemic indolines with multiple stereocenters and diverse substituent patterns in high efficiency with efficient chemoselectivity and enantio-discrimination. Late-stage asymmetric oxygenation of bioactive molecules that are otherwise difficult to synthesize was also explored.

\footnotetext{
${ }^{1}$ School of Chemistry and Chemical Engineering, Shandong University, Jinan, China. ${ }^{2}$ School of Pharmaceutical Sciences, Jinan, China. ${ }^{凶}$ email: leiliu@sdu.edu.cn
} 
nantiopure cyclic secondary amines are key constituents of natural products, pharmaceuticals, and agricultural chemicals ${ }^{1}$. Catalytic kinetic resolution (KR) of racemic amines represents a practical and robust approach to access optically pure targets, especially in cases where the racemates are readily available and the enantiopure materials are not ${ }^{2-8}$, though the theoretical yield of the expected optically pure target can never exceed a limit of $50 \%{ }^{9-11}$. The current nonenzymatic KR of secondary amines predominantly relies on asymmetric $N$-acylation strategy involving $\mathrm{N}-\mathrm{C}$ bond formation, which typically requires the use of stoichiometric pre-prepared acylating agents involving lengthy reagent synthesis (Fig. 1a) ${ }^{12-18}$. Development of a catalytic KR of secondary amines based on other elementary reaction bearing an economy-oriented mind-set would be highly desirable.

Oxygen atom transfer (OAT) reaction is ubiquitous in biological systems, organic synthesis, and industrial processes ${ }^{19-23}$. Current asymmetric OAT studies predominantly focused on oxygenation of alkenes and sulfides involving $\mathrm{C}-\mathrm{O}$ and $\mathrm{S}-\mathrm{O}$ bond formation ${ }^{24-34}$. We envisioned that asymmetric OAT to secondary amines to produce enantiopure hydroxylamines involving $\mathrm{N}-\mathrm{O}$ bond formation would be an ideal template for KR design based on economical and environmental factors (Fig. 1b). However, asymmetric OAT to amines has remained a formidable challenge $e^{35,36}$. To the best of our knowledge, asymmetric oxygenation of secondary amines to produce hydroxylamines through either enzymatic or non-enzymatic catalysis has never been established to date, which might be ascribed to three key challenges. First, the inherent high reactivity of amines results in easy nonselective oxygenation without the intervention by a catalyst. Second, competitive dehydrogenation of secondary amines to imines usually accompanies the expected OAT process ${ }^{37-39}$. Third, chirality in hydroxylamine products could be facilely destroyed through further oxidation to nitrones ${ }^{40}$. On the other hand, aqueous hydrogen peroxide is a desirable oxidant from the viewpoints of atom efficiency (48\%), easy-to-handle, and ecological benignity ${ }^{32,41}$. Given the significance of optically pure indolines in modern pharmacology, we herein report a titanium-catalyzed $\mathrm{KR}$ of indolines using $\mathrm{H}_{2} \mathrm{O}_{2}$ as the oxidant through $\mathrm{N}-\mathrm{O}$ bond formation. Late- stage asymmetric oxygenation of bioactive molecules that are otherwise difficult to synthesize was also explored.

\section{Results}

Reaction condition optimization. Initially, asymmetric oxygenation of racemic indoline 1a was selected as a reference reaction using aqueous $\mathrm{H}_{2} \mathrm{O}_{2}$ as the oxo-transfer agent to search for a suitable chiral catalyst (Table 1). Chiral monomeric (salen)titanium(IV) C1 exhibited no oxidation catalysis reactivity (entry 1). We then explored dimeric metallosalen complex as catalyst. Delightedly, di- $\mu$-oxo titanium(salen) $\mathbf{C 2}$ effected the expected asymmetric oxygenation, though poor chiral recognition and notable over-oxidation were observed (entry 2). The substituent patterns on 1,2-ethanediamine proved to be crucial to catalytic reactivity and asymmetric induction. Replacing the 1,2-cyclohexanediamine moiety in $\mathbf{C 2}$ with 1,2-diphenylethylenediamine one (C3) significantly reduced the oxidation catalytic reactivity (entry 3). Di- $\mu$-oxo titanium(salalen) C4 was prepared by reducing one of the process (entry 4). Displacing the phenyl group on salicylaldehydes with other two imine bonds of $\mathbf{C 2}$, was beneficial for suppressing undesired over-oxidation substituents afforded inferior results, which prompted us to introduce another chiral element at $\mathrm{C}_{3}$ site of the basal salalen ligand to enhance the enantio-differentiating ability of the catalyst. The "hybrid" titanium(salalen) C5 bearing a $\left(R_{\mathrm{a}}\right)$-binaphthyl unit on the imine side was not an effective catalyst (entry 5). Promising chiral recognition was observed when di- $\mu$-oxo titanium(salalen) catalyst $\mathbf{C 6}$ bearing two $\left(R_{\mathrm{a}}\right)$-binaphthyl units on both amine and imine sides were used (entry 6). The absolute configuration of (R)-1a was assigned to be $R$ by comparing the optical rotation and HPLC analysis with reported data. See the Supplementary Information for details. Reversing the absolute configuration of 1,2-cyclohexanediamine in catalyst $\mathbf{C} 7$ provided a mismatch recognition (entry 7). Extensive optimization of the solvent identified $\mathrm{CHCl}_{3}$ to be optimal (entries 8-10). The level of chiral discrimination was further enhanced by lowering the loading of titanium(salalen) C6 from $2.5 \mathrm{~mol} \%$ to $1.0 \mathrm{~mol} \%$, though a slightly prolonged time period was required (entry 11).

a) Asymmetric acylation strategy via N-C bond formation (Fu, Hou, Bode, Kozlowski)
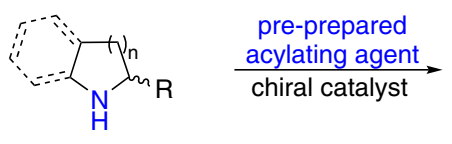<smiles>[R]C1Nc2ccccc2N1</smiles><smiles>[R]C(=O)N1c2ccccc2NC1[R]</smiles>

b) Asymmetric oxygenation strategy via $\mathrm{N}-\mathrm{O}$ bond formation (this work)<smiles>PC1Cc2ccccc2N1</smiles>
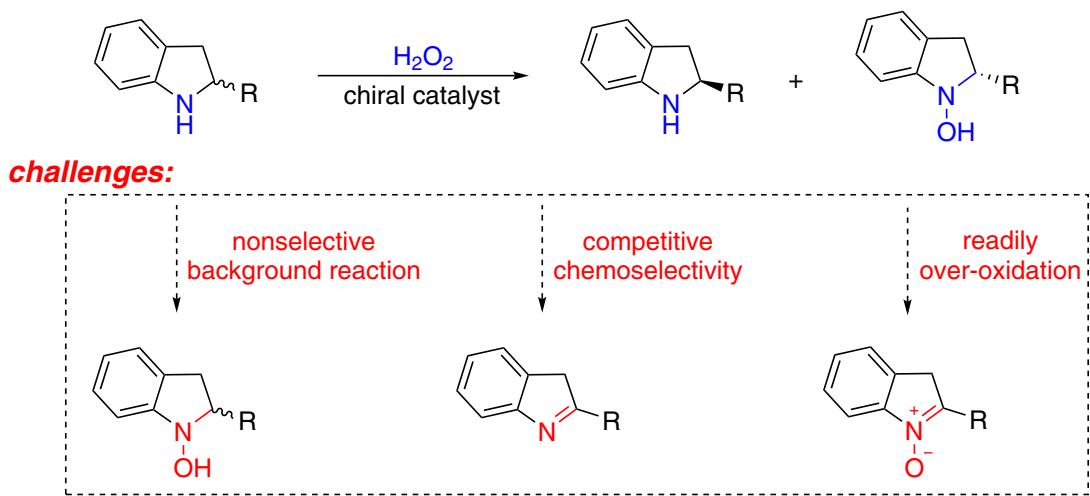

Fig. 1 Overview of KR of cyclic secondary amines. a Asymmetric acylation strategy via N-C bond formation. b Asymmetric oxygenation strategy via N-O bond formation. 
Table 1 Reaction condition optimizationa.
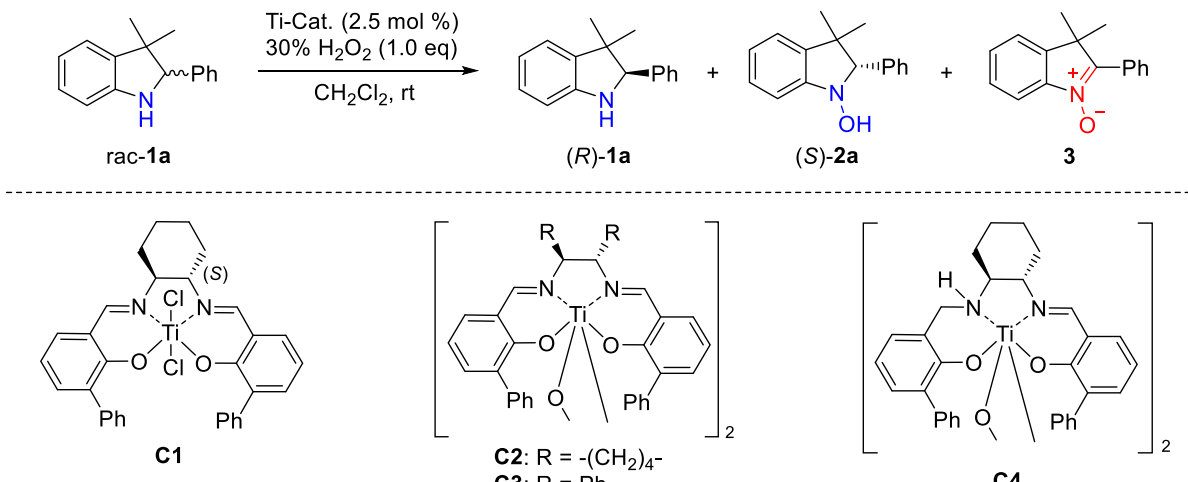

C3: $\mathrm{R}=\mathrm{Ph} \quad \mathrm{C} 4$

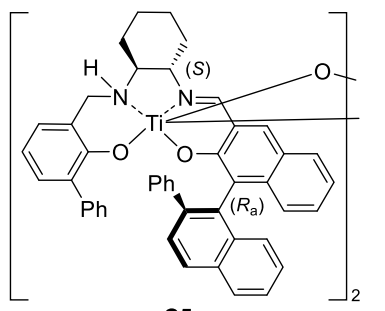

C5
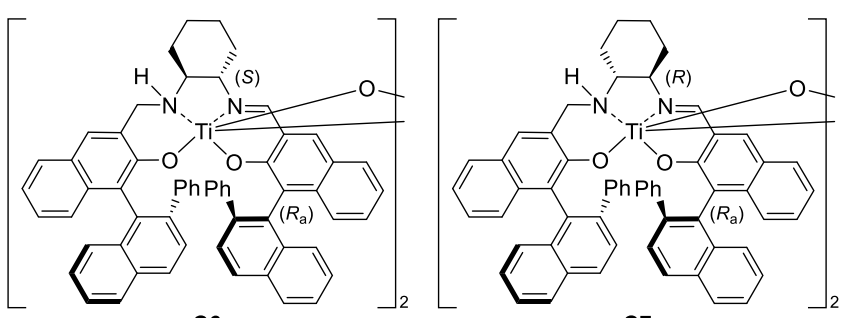

C7

\begin{tabular}{|c|c|c|c|c|c|}
\hline Entry & Cat. & $t(h)$ & $\begin{array}{l}\text { Yield }(\%)^{b} \\
1 a / 2 a / 3\end{array}$ & $\begin{array}{l}\text { ee }(\%)^{c} \\
(R)-1 a /(S)-2 a\end{array}$ & $s^{d}$ \\
\hline$\overline{1}$ & C1 & 24 & $\begin{array}{l}>95 /<5 / \\
<5\end{array}$ & n.d. & n.d. \\
\hline 3 & C3 & 24 & $\begin{array}{l}>95 /<5 / \\
<5\end{array}$ & n.a. & n.a. \\
\hline 4 & C4 & 1 & $48 / 32 / 13$ & $43 / 45$ & 3.9 \\
\hline 7 & C7 & 12 & $78 / 9 / 8$ & $7 / 30$ & 2 \\
\hline $8^{e}$ & C6 & 12 & $67 / 17 / 9$ & $37 / 90$ & 28 \\
\hline $9^{f}$ & $\mathrm{C} 6$ & 12 & $51 / 36 / 9$ & $65 / 75$ & 14 \\
\hline $10 \mathrm{~g}$ & $\mathrm{C} 6$ & 4 & $47 / 43 / 5$ & $94 / 89$ & 60 \\
\hline $11 g^{\prime h}$ & $\mathrm{C} 6$ & 6 & $47 / 45 / 3$ & $92 / 92$ & 79 \\
\hline
\end{tabular}

aReaction condition: rac-1a $(0.1 \mathrm{mmol}), 30 \%$ aqueous $\mathrm{H}_{2} \mathrm{O}_{2}(0.1 \mathrm{mmol})$, and catalyst $(2.5 \mathrm{~mol} \%)$ in $\mathrm{CH}_{2} \mathrm{Cl}_{2}(1.0 \mathrm{~mL})$ at rt for indicated time period, unless otherwise noted. bYield of isolated product. 'Determined by HPLC analysis on a chiral stationary phase. ${ }^{\mathrm{d} S e l e c t i v i t y}(s)$ values were calculated through the equation $s=\ln \left[(1-C)\left(1-e_{1}\right)\right] / \ln \left[(1-C)\left(1+e_{1}\right)\right]$, where $C$ is the conversion; $C=e_{1} \mathbf{a} /$ $\left(e e_{\mathbf{a}}+e_{\mathbf{2 a}}\right)$. ${ }^{e}$ Ethyl acetate as solvent. ${ }^{\mathrm{f}} \mathrm{CH}_{3} \mathrm{CN}$ as solvent. ${ }^{\mathrm{g}} \mathrm{CHCl}_{3}$ as solvent. ${ }^{\mathrm{h}} 1 \mathrm{~mol} \%$ of $\mathbf{C} \mathbf{6}$ used.

Asymmetric oxygenation of indolines bearing one stereocenter. The scope of di- $\mu$-oxo titanium(salalen)-catalyzed asymmetric oxygenation of racemic indolines was explored (Fig. 2) ${ }^{40}$. Substrates 1a-1k bearing a wide range of electronically varied aryl and heteroaryl groups at $C_{2}$ position with different substituent patterns proceeded with excellent chemoselectivity and chiral recognition (Fig. 2a). Indolines 11-1s bearing diverse $C_{2}$-alkyl substituents were suitable components with excellent selectivity factors (Fig. 2b). Diverse functional groups including phenyl motif (1o and 1p), silyl ether (1q), carboxylic acid ester (1) terminal alkyne (1s) were tolerated as additional functional handle. Spirocyclic 1r and 1s containing the variant of the geminal disubstitution at $\mathrm{C}_{3}$-position were also tolerated (Fig. 2c). Simple indoline 1t without $\mathrm{C}_{3}$-substituent was competent substrate, though the oxidized hydroxylamine $\mathbf{2 t}$ was unstable and underwent decomposition during purification probably due to the existence of reactive benzylic $\mathrm{C}_{3}-\mathrm{H}$ bonds.

The substituent effects on the indoline arene were then investigated (Fig. 3). A range of electron-withdrawing and -donating substituents at either $\mathrm{C}_{4}, \mathrm{C}_{5}$, or $\mathrm{C}_{6}$ position of substrates $\mathbf{4 a}-\mathbf{4 j}$ were tolerated with high level of chiral discrimination (Fig. 3). Bromo (4a-4c), chloro (4d), and fluoro (4e) substituents were compatible with the oxidation system for further diversification.

Scope of indolines bearing two stereocenters. The success in asymmetric oxygenation of racemic indolines bearing one stereocenter prompted us to further investigate the tolerance of substrates bearing two stereocenters (Fig. 4) ${ }^{42-47}$. Enantiodifferentiating oxygenation of trans-2,3-trisubstituted indoline rac-6a bearing $\mathrm{C}_{3}$ quaternary chiral center proceeded smoothly, providing $(2 R, 3 S)-6 a$ in $46 \%$ yield with $88 \%$ ee together with hydroxylamine $(2 S, 3 R)-7 \mathbf{a}$ in $45 \%$ yield with $93 \%$ ee $(s=81)$. Cis-2,3-trisubstituted indoline rac-6b was also compatible with the asymmetric oxygenation conditions $(s=46)$. Common functional groups at the $\mathrm{C}_{3}$ quaternary center, like aryl (6c-6f) and cyano (6f and $\mathbf{6 g}$ ), were well tolerated with good selectivity factors of 49-87. Cyclohexane-fused indolines, key structural motifs in a number of Aspidosperma alkaloids, were competent 


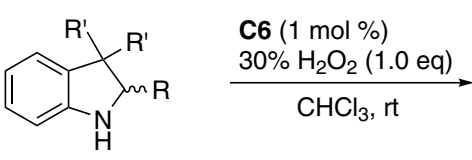

rac-1<smiles>[R]C1Nc2ccccc2C1([R])[R]</smiles>

(R)-1

(S)-2

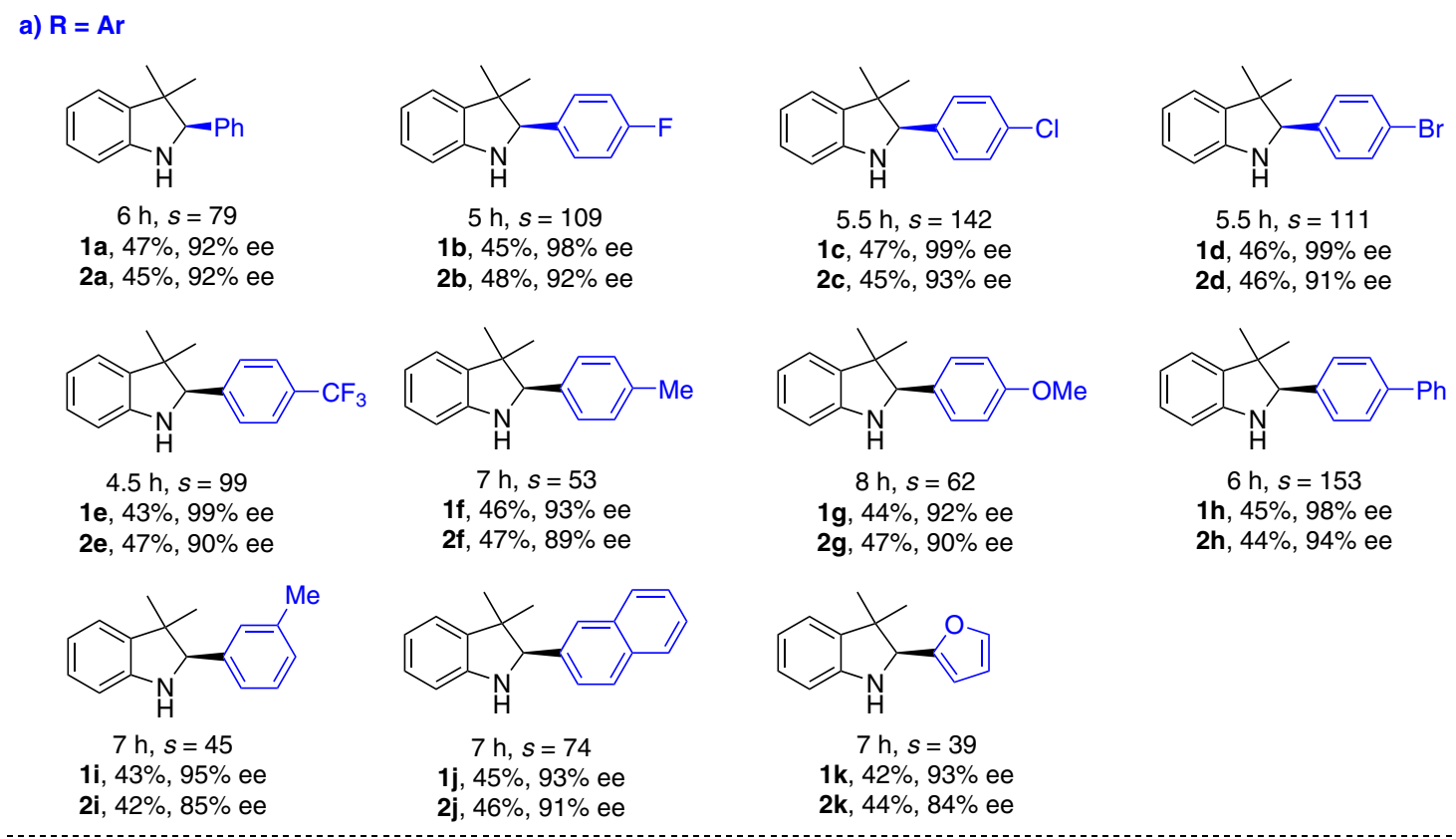

b) $\mathbf{R}=$ alkyl<smiles>CCC1Nc2ccccc2C1(C)C</smiles>

$7 \mathrm{~h}, s=71$ 1I, $46 \%, 89 \%$ ee 2I, $47 \%, 92 \%$ ee<smiles>CC1(C)c2ccccc2NC1CCc1ccccc1</smiles>

$7 \mathrm{~h}, s=61$ 1p, $42 \%, 96 \%$ ee 2p, $49 \%, 88 \%$ ee

c) variant of $R^{\prime}$<smiles>c1ccc([C@@H]2Nc3ccccc3C23CCCC3)cc1</smiles>

$12 \mathrm{~h}, s=31^{\mathrm{a}}$

1t, $44 \%, 85 \%$ ee

2t, $42 \%, 84 \%$ ee

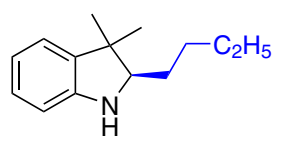

$7 \mathrm{~h}, s=69$ $1 \mathrm{~m}, 45 \%, 92 \%$ ee 2m, $44 \%, 91 \%$ ee

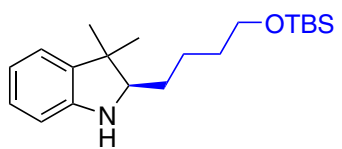

$7 \mathrm{~h}, s=53$

1q, $44 \%, 95 \%$ ee 2q, $50 \%, 87 \%$ ee<smiles>CC(C)C1Nc2ccccc2C1(C)C</smiles>

$8 \mathrm{~h}, s=25$

1n, $43 \%, 80 \%$ ee

2n, $46 \%, 82 \%$ ee

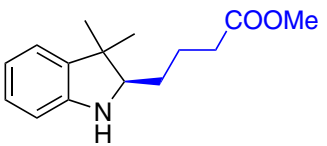

$7 \mathrm{~h}, s=50$

1r, $40 \%, 91 \%$ ee 2r, $45 \%, 88 \%$ ee

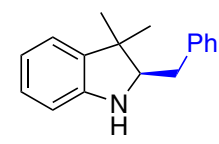

$7 \mathrm{~h}, \mathrm{~s}=76$

1o, $45 \%, 94 \%$ ee

2o, $46 \%, 91 \%$ ee

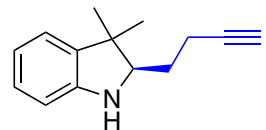

$7 \mathrm{~h}, \mathrm{~s}=70$

1s, $47 \%, 95 \%$ ee

2s, $45 \%, 90 \%$ ee

Fig. 2 Asymmetric oxygenation of racemic $\mathbf{C}_{\mathbf{2}}$-substituted indolines. Conditions: rac-1 $(0.1 \mathrm{mmol}), 30 \%$ aqueous $\mathrm{H}_{2} \mathrm{O}_{2}(0.1 \mathrm{mmol})$, and $\mathbf{C 6}(1 \mathrm{~mol} \%)$ in $\mathrm{CHCl}_{3}(1.0 \mathrm{~mL})$ at $\mathrm{rt}$ for indicated time period. aReaction with 2.0 equiv of aqueous $\mathrm{H}_{2} \mathrm{O}_{2}$ at $0^{\circ} \mathrm{C}$.

substrates, as demonstrated by effective enantio-differentiating oxygenation of $\mathbf{r a c}-\mathbf{6 h}$ and $\mathbf{6 i}^{48-50}$. Trans-2,3-disubstituted indoline rac-6j participated in asymmetric oxygenation, and $(2 S$, $3 S$ )-6j was recovered in $42 \%$ yield with $84 \%$ ee. Due to the existence of reactive benzylic $\mathrm{C}_{3}-\mathrm{H}$ bond, the oxidized hydroxylamine $7 \mathbf{j}$ was not stable under the oxidation conditions, and was further oxidized to several unexpected compounds (see the Supplementary Information for details $)^{51}$.
Synthetic applications. The synthetic utilities of the method were next examined (Fig. 5). The optically pure recovered indolines and oxidized hydroxylamines can undergo interconversion with the ee highly conserved. Hydroxylamine $(S)$-2a was reduced to (S)-1a in the presence of $\mathrm{Zn}$ and $\mathrm{AcOH}$ (Fig. 5a). The absolute configuration of $(S)$-2a was assigned to be $S$ by HPLC analysis of the reduction product $(S)$-1a. See the Supplementary Information for details. Indoline $(R)$-1a was selectively oxidized to 


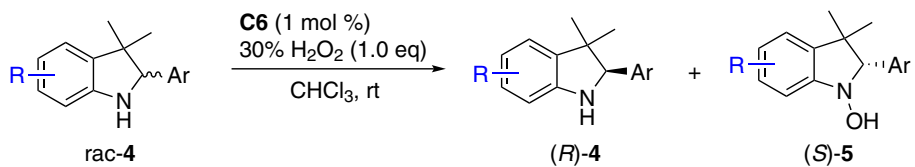

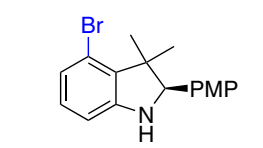

$5.5 \mathrm{~h}, s=114$

4a, $48 \%, 89 \%$ ee

5a, $44 \%, 95 \%$ ee<smiles>CC1(C)c2cc(Cl)ccc2NC1c1ccccc1</smiles>

$4 \mathrm{~h}, s=128$

4 e, $43 \%, 99 \%$ ee 5e, $46 \%, 92 \%$ ee

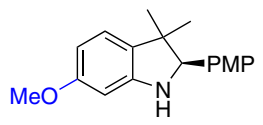

$5 \mathrm{~h}, s=53$

$4 i, 44 \%, 93 \%$ ee

5i, $40 \%, 88 \%$ ee

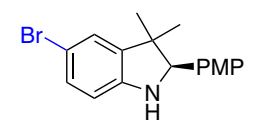

$4 \mathrm{~h}, s=113$

$4 b, 44 \%, 97 \%$ ee

5b, $47 \%, 93 \%$ ee

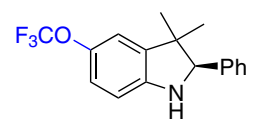

$5 \mathrm{~h}, \mathrm{~s}=71$

4f, $42 \%, 97 \%$ ee

5f, $46 \%, 89 \%$ ee

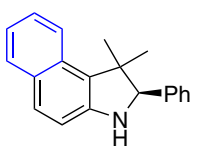

$5 \mathrm{~h}, s=74$

4 j, $43 \%, 93 \%$ ee

5j, $41 \%, 91 \%$ ee

(S)-5

Fig. 3 Substituent effects on the indoline arene. Conditions: rac- $4(0.1 \mathrm{mmol}), 30 \%$ aqueous $\mathrm{H}_{2} \mathrm{O}_{2}(0.1 \mathrm{mmol})$, and $\mathbf{C 6}(1 \mathrm{~mol} \%)$ in $\mathrm{CHCl} 3(1.0 \mathrm{~mL})$ at $\mathrm{rt}$ for indicated time period.

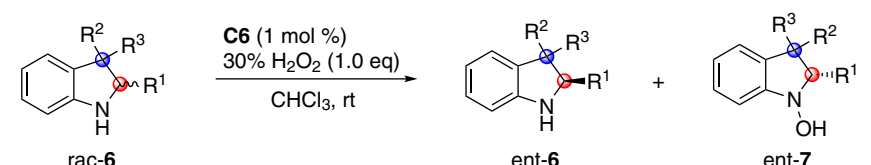

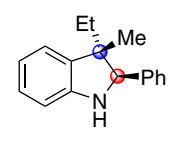

$6 \mathrm{~h}, \mathrm{~s}=81$

6a, $46 \%, 88 \%$ ee

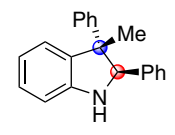

$6.5 \mathrm{~h}, \mathrm{~s}=65$

6c, $43 \%, 94 \%$ ee

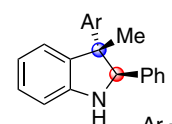

$\mathrm{Ar}$

$6.5 \mathrm{~h}, \mathrm{~s}=49$

$6 e, 44 \%, 87 \%$ ee

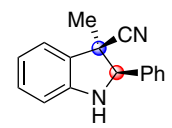

$5.5 \mathrm{~h}, \mathrm{~s}=78$

$6 \mathrm{~g}, 42 \%, 95 \%$ ee

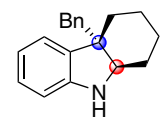

$10 \mathrm{~h}, \mathrm{~s}=52^{\mathrm{a}}$

$6 i, 47 \%, 86 \%$ ee

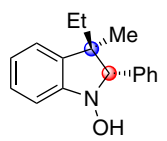

7a, $45 \%, 93 \%$ ee

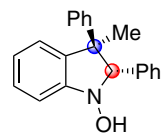

$7 c, 45 \%, 87 \%$ ee

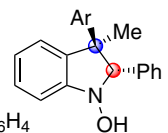

$\mathrm{OH}$

7e, $45 \%$, $89 \%$ ee

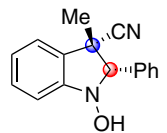

7g, $46 \%, 91 \%$ ee<smiles></smiles>

7i, $44 \%, 90 \%$ ee

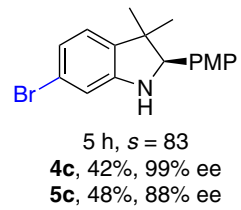<smiles>CC1(C)c2cc(F)ccc2NC1c1ccccc1</smiles>

$4 \mathrm{~h}, s=99$

4d, $43 \%, 99 \%$ ee

5d, $47 \%, 90 \%$ ee

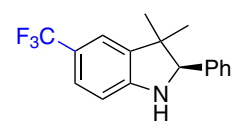

$4 \mathrm{~h}, \mathrm{~s}=147$

4g, $49 \%, 88 \%$ ee

$5 \mathrm{~g}, 40 \%, 96 \%$ ee

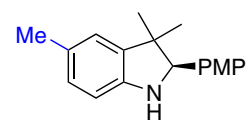

$4 \mathrm{~h}, s=51$

4h, $41 \%, 94 \%$ ee

5h, $43 \%, 87 \%$ ee

ent- 6

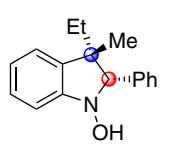

$\mathrm{OH}$

$8 \mathrm{~h}, \mathrm{~s}=46$

6b, $44 \%, 91 \%$ ee

7b, $46 \%, 87 \%$ ee

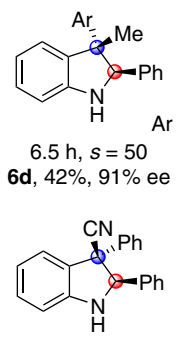

$7.5 \mathrm{~h}, \mathrm{~s}=87$

6f, $46 \%, 94 \%$ ee

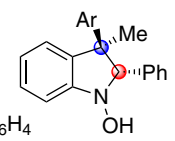

$\mathrm{r}=4-\mathrm{ClC}_{6} \mathrm{H}_{4}$

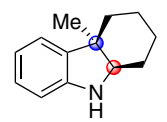

$10 \mathrm{~h}, s=32^{a}$ 6h, $45 \%, 86 \%$ ee<smiles></smiles>

7f, $45 \%, 92 \%$ ee<smiles>C[C@@H]1CCC[C@@H]2N(O)c3ccccc3N21</smiles>

7h, $43 \%, 84 \%$ ee

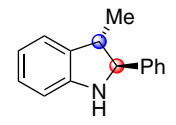

$12 \mathrm{~h}, s=11^{\mathrm{a}}$ 6 j, $42 \%, 84 \%$ ee

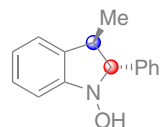

$\mathrm{OH}$

$7 \mathbf{j}$

Fig. 4 Scope of indolines bearing two stereocenters. Conditions: rac-6 $(0.1 \mathrm{mmol}), 30 \%$ aqueous $\mathrm{H}_{2} \mathrm{O}_{2}(0.1 \mathrm{mmol})$, and $\mathbf{C 6}(1 \mathrm{~mol} \%)$ in $\mathrm{CHCl}(1.0 \mathrm{~mL})$ at rt for indicated time period. aReaction with 2.0 equiv of aqueous $\mathrm{H}_{2} \mathrm{O}_{2}$ at $0^{\circ} \mathrm{C}$. 


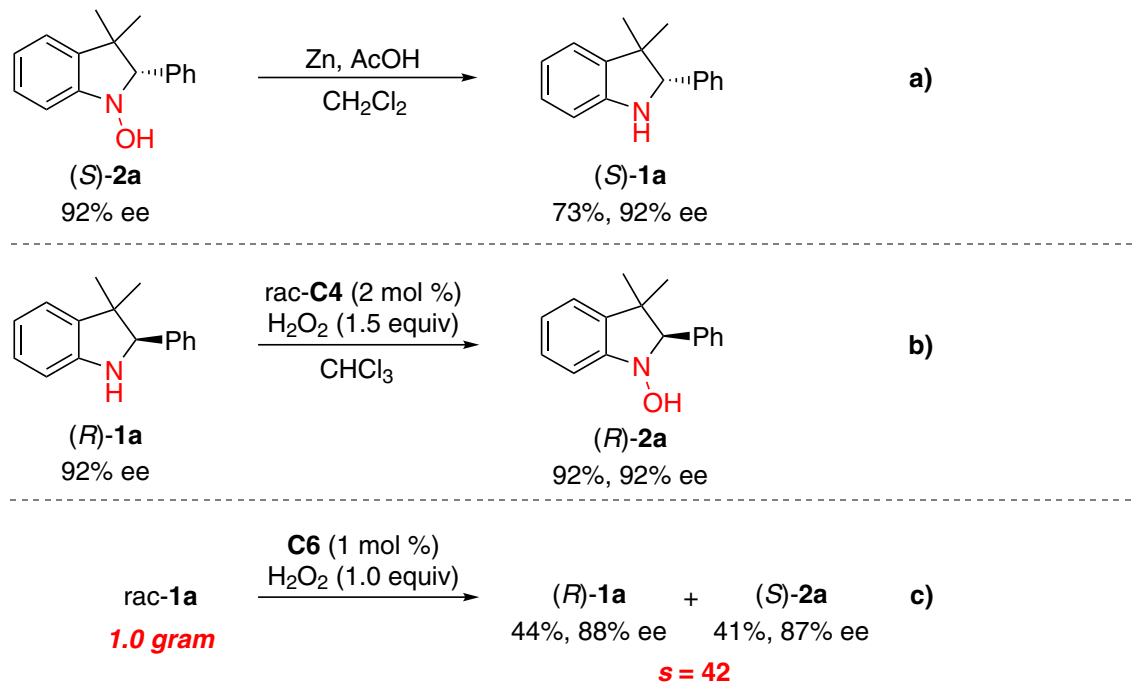

d)

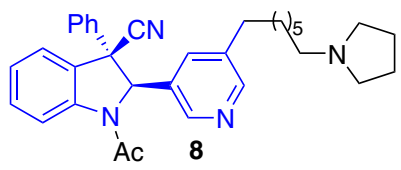

selective inhibitor of KDM2A/7A

$(2 R, 3 R)-8: \mathrm{IC}_{50} 0.39 \mu \mathrm{M}$

$(2 S, 3 S)-8: I_{50} 0.16 \mu \mathrm{M}$<smiles>N#C[C@]1(c2ccccc2)c2ccccc2NC1c1cncc(Br)c1</smiles>

rac-9

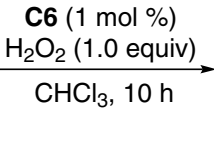

$s=85$<smiles>N#C[C@@]1(c2ccccc2)c2ccccc2N[C@H]1c1cncc(Br)c1</smiles>

(2R,3R)-9

$45 \%, 96 \%$ ee<smiles>N#C[C@]1(c2ccccc2)c2ccccc2N(O)[C@H]1c1cncc(Br)c1</smiles>

(2S,3S)-10

e)<smiles>[R]c1ccc2c(c1)C1(CCNCC1)C(C1CC1)N2OS(=O)(=O)O</smiles><smiles>O=C(O)N1CCC2(CC1)c1cc(Br)ccc1NC2C1CC1</smiles>

rac-12

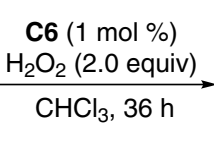

$s=23$<smiles>O=C(c1ccccc1)N1CCC2(CC1)c1cc(Br)ccc1NC2C1CC1</smiles>

(R)-12<smiles>O=C(O)[N+]1CCC2(CC1)C(C1CC1)=[N+]([O-])c1ccc(Br)cc12</smiles>

13, $45 \%$

$49 \%, 83 \%$ ee

Fig. 5 Synthetic applications. a Reduction of hydroxylamine (S)-2a. b Oxidation of indoline (R)-1a. c Gram-scale experiment. d Late-stage enantiodifferentiating oxygenation intermediates of KDM2A/7A. e Late-stage enantio-differentiating oxygenation intermediates of GnRH antagonists.

hydroxylamine $(R)-1 \mathbf{a}$ in $92 \%$ yield when the combination of racemic titanium(salalen) $\mathbf{C} 4$ and aqueous $\mathrm{H}_{2} \mathrm{O}_{2}$ was employed (Fig. 5b). Severe over-oxidation to nitrone was observed when common oxidants such as 3-chloroperoxybenzoic acid (mCPBA), $\mathrm{NaWO}_{4} / \mathrm{H}_{2} \mathrm{O}_{2}$, and methyltrioxorhenium $(\mathrm{MTO}) / \mathrm{H}_{2} \mathrm{O}_{2}$, were used. The reaction in a gram-scale proceeded without obvious loss of enantioselectivity (Fig. 5c). The late-stage enantio-differentiating oxygenation advanced intermediates of bioactive molecules that would be otherwise difficult to access was further explored. Trans-2,3-trisubstituted indoline $\mathbf{8}$ was identified as a potent and selective inhibitor of the histone lysine demethylases KDM2A/7A (Fig. 5d) ${ }^{52}$. Under the standard conditions, rac-9 


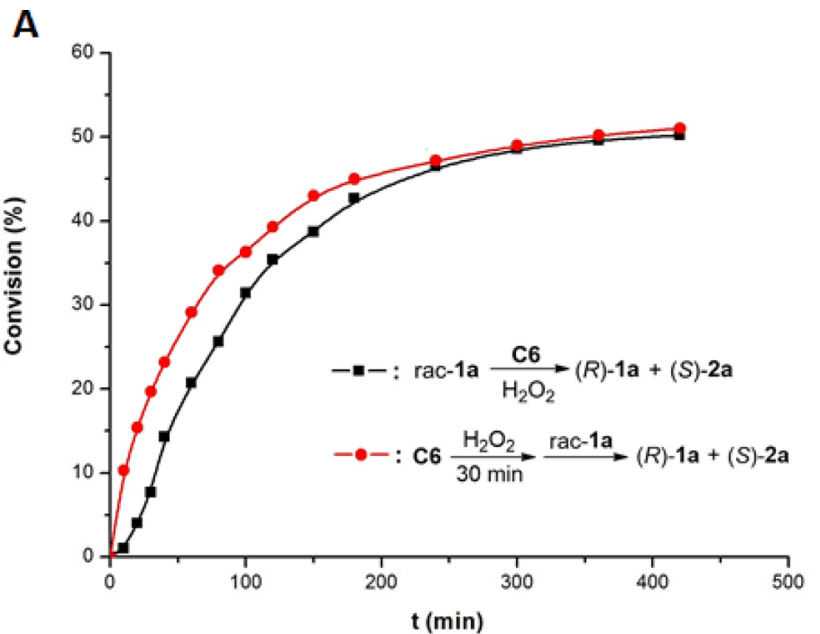

C

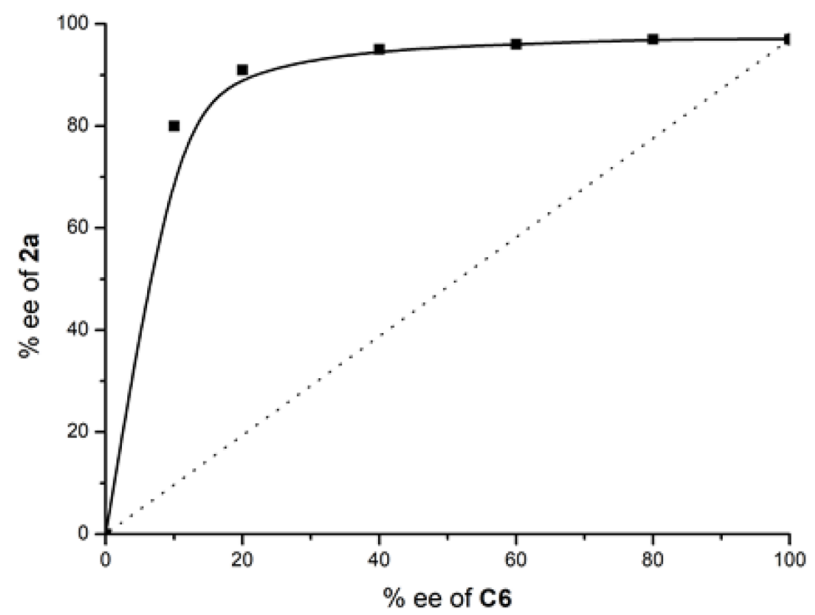

B

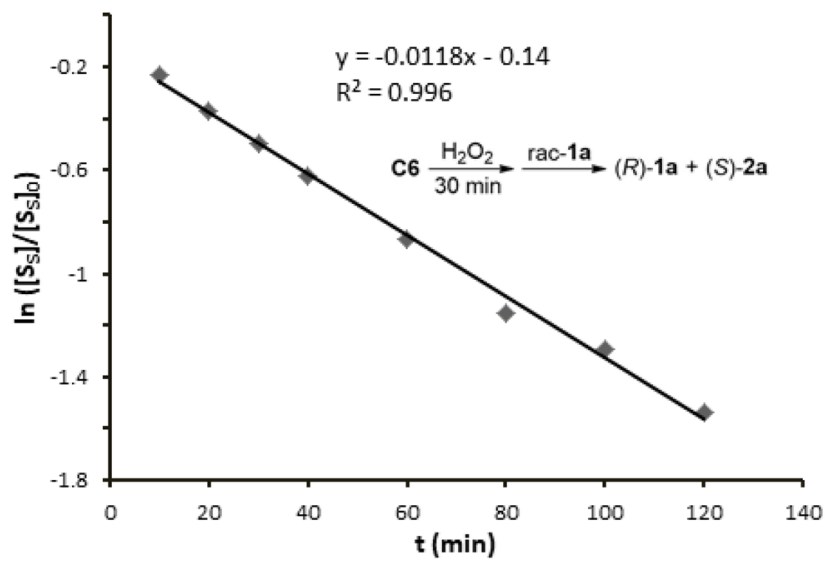

D

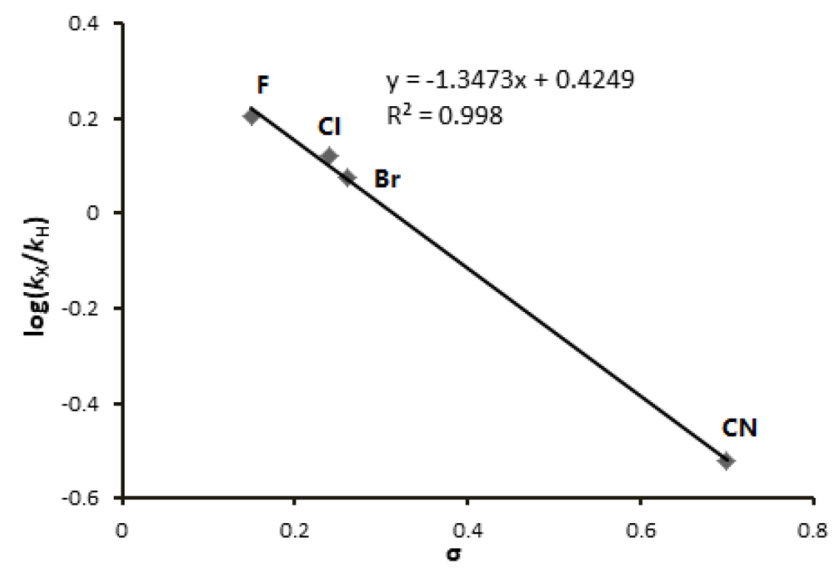

Fig. 6 Mechanistic studies. A Kinetic plots for the oxygenation of rac-1a with $\mathbf{C 6} / \mathrm{H}_{2} \mathrm{O}_{2}$. B $\ln \left(\left[\mathrm{S}_{\mathrm{S}}\right] /\left[\mathrm{S}_{\mathrm{S}}\right]_{0}\right)$ versus time dependences for the oxygenation of

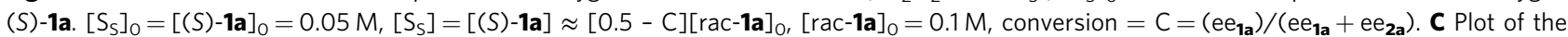
enantiomeric excess of $\mathbf{2 a}$ versus the enantiomeric excess of $\mathbf{C} \mathbf{6}$ at $50 \%$ conversion. The dotted line symbolizes the linear correlation. D Hammett plot of $\log \left(k_{X} / k_{\mathrm{H}}\right)$ vs $\sigma$ for the competitive oxidation of $\mathrm{C}_{5}$-substituted indolines by $\mathbf{C 6} / \mathrm{H}_{2} \mathrm{O}_{2}$.

participated in the asymmetric oxygenation reaction, furnishing $(2 R, 3 R)-9$ in $45 \%$ yield with $96 \%$ ee together with $(2 S, 3 S)-10$ in $47 \%$ yield with $91 \%$ ee $(s=85)$ (Fig. 5 d). $C_{2}$-Cyclopropane-substituted indoline $\mathbf{1 1}$ was discovered as a general pharmacophore for gonadotropin-releasing hormone (GnRH) antagonists (Fig. 5e $)^{53}$. Asymmetric oxidation of rac-12 proved to be relatively sluggish, and when 2.0 equiv of aqueous $\mathrm{H}_{2} \mathrm{O}_{2}$ was used, $(R)-12$ was recovered in $49 \%$ yield with $83 \%$ ee $(s=23)$ together with over-oxidized nitrone $\mathbf{1 3}$ in $45 \%$ yield (Fig. $5 \mathrm{e}$ ).

\section{Discussion}

To get a preliminary understanding of the catalysis role of titanium(salalen) $\mathbf{C 6}$ in asymmetric oxygenation of indolines, conversion (\%) of rac-1a was plotted against time ( $\mathrm{min}$ ) for reaction under standard conditions and that with pre-mixed catalyst and $\mathrm{H}_{2} \mathrm{O}_{2}$, respectively (Fig. 6A). For the standard reaction, conversion followed a sigmoidal curve, and an induction period of about $30 \mathrm{~min}$ was observed. Such induction period was not observed in the reaction using pre-mixed $\mathbf{C 6}$ and $\mathrm{H}_{2} \mathrm{O}_{2}$, suggesting that the generation of the real active species for oxygenation reaction is a slow process. Moreover, the latter reaction exhibited an apparent steady-state regime, resulting in linear $\ln \left(\left[\mathrm{S}_{S}\right] /\left[\mathrm{S}_{S}\right]_{0}\right)$ vs. time dependence (Fig. 6B).
Control experiments were performed to further understand the identity of the generated species by mixing $\mathbf{C 6}$ with $\mathrm{H}_{2} \mathrm{O}_{2}$. The relationship between the excesses of $\mathbf{2 a}$ and the catalyst $\mathbf{C 6}$ was investigated, and a positive nonlinear relationship was observed, suggesting the possible intervention of a dimeric complex (Fig. 6C) ${ }^{54,55}$. ESI mass-spectrometry analysis of the mixture of di$\mu$-oxo titanium(salalen) $\mathbf{C} 6$ and $30 \%$ aqueous $\mathrm{H}_{2} \mathrm{O}_{2}$ after $30 \mathrm{~min}$ showed the peak of 1797.6, which is equal to $\left[\mathrm{M}_{\mathbf{C 6}}+\mathrm{O}+\mathrm{H}\right]^{+}$, implying the formation of a $\mu$-oxo- $\mu$-peroxo species $\mathbf{S}$ (Fig. $7 \mathrm{a})^{56}$. However, a lower intensity of this peak was observed for mixing $\mathbf{C 6}$ and $\mathrm{H}_{2} \mathrm{O}_{2}$ after $15 \mathrm{~min}$, implying that the formation of $\mathbf{S}$ might be a slow process. No reaction was observed when mixing one equiv of $\mathbf{S}$ with rac-1a (Fig. $7 \mathrm{~b}$ ). However, the addition of aqueous hydrogen peroxide rendered $\mathbf{S}$ catalytically active with comparable results to $\mathbf{C 6}$ (Fig. 7c). These results clearly indicate that $\mathbf{S}$ is neither the real active species nor a dead-end species but an active intermediate. Crossover experiments involving two different catalysts C4 and C6 were next performed. Mass spectra analysis of equivalent $\mathbf{C 4}$ and $\mathbf{C 6}$ in the presence of $30 \%$ aqueous $\mathrm{H}_{2} \mathrm{O}_{2}$ showed the peak of 1445.5 , which is equal to $\left[\mathrm{M}_{\mathrm{C} 4} / 2+\mathrm{M}_{\mathrm{C} \sigma} / 2+\right.$ $\mathrm{O}+\mathrm{H}]^{+}$, suggesting the generation of a crossover dimerization peroxo complex (Fig. 7d). No such peak was detected during the mass spectra analysis of the mixture of $\mathbf{C 4}$ and $\mathbf{C 6}$ in the absence of $\mathrm{H}_{2} \mathrm{O}_{2}$ (Fig. 7e). These observations indicated that a disassembly 
a) ESI-MS analysis of the mixture of $\mathbf{C 6}$ and $\mathrm{H}_{2} \mathrm{O}_{2}$

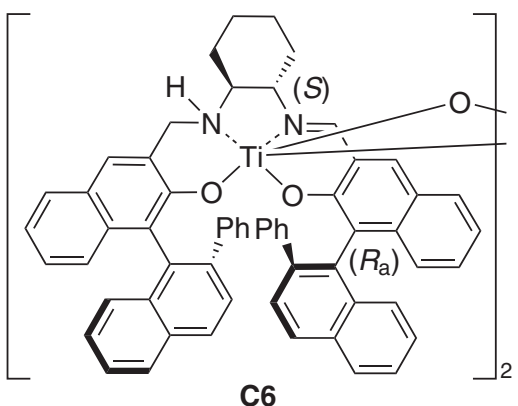

$[\mathrm{M}+\mathrm{H}]^{+}=1781.6$

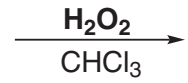

$\mu$-oxo- $\mu$-peroxo species

$m / z=1797.6$

b) The oxidation reactivity of stoichiometric $\mathrm{S}$ without $\mathrm{H}_{2} \mathrm{O}_{2}$

rac-1a $\underset{\mathrm{CHCl}_{3}}{\stackrel{\mathbf{S}(1.0 \mathrm{eq})}{\longrightarrow}}$ no reaction

c) The oxidation catalysis reactivity of $\mathrm{S}$ with $\mathrm{H}_{2} \mathrm{O}_{2}$

$$
\begin{aligned}
& \text { rac-1a } \stackrel{\begin{array}{c}
\mathrm{S}(1 \mathrm{~mol} \%) \\
\mathrm{H}_{2} \mathrm{O}_{2}(1.0 \mathrm{eq})
\end{array}}{\mathrm{CHCl}_{3}} \quad \begin{array}{c}
(R)-1 \mathrm{a} \\
44 \%, 91 \% \text { ee }
\end{array}+\begin{array}{c}
(S)-2 \mathrm{a} \\
46 \%, 90 \% \text { ee }
\end{array} \\
& s=60
\end{aligned}
$$

d) ESI-MS analysis of the mixture of $\mathbf{C 4}, \mathbf{C 6}$, and $\mathrm{H}_{2} \mathrm{O}_{2}$

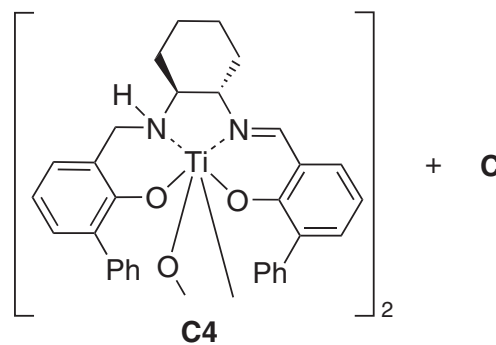

C6

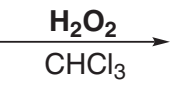

crossover dimerization

peroxo species

$m / z=1445.5$

$[\mathrm{M}+\mathrm{H}]^{+}=1077.3$

e) ESI-MS analysis of the mixture of $\mathbf{C 4}$ and $\mathbf{C 6}$ without $\mathrm{H}_{2} \mathrm{O}_{2}$

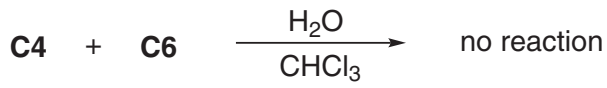

Fig. 7 Control experiments of titanium(salalen) catalyst with aqueous $\mathbf{H}_{\mathbf{2}} \mathbf{O}_{\mathbf{2}}$. a ESI-MS analysis of the mixture of $\mathbf{C} 6$ and $\mathrm{H}_{2} \mathrm{O}_{2}$. $\mathbf{b}$ The oxidation reactivity of stoichiometric $\mathbf{S}$ without $\mathrm{H}_{2} \mathrm{O}_{2}$. c The oxidation catalysis reactivity of $\mathbf{S}$ with $\mathrm{H}_{2} \mathrm{O}_{2}$. $\mathbf{d}$ ESI-MS analysis of the mixture of $\mathbf{C 4}$, $\mathbf{C 6}$, and $\mathrm{H}_{2} \mathrm{O}_{2}$. e ESI-MS analysis of the mixture of $\mathbf{C 4}$ and $\mathbf{C 6}$ without $\mathrm{H}_{2} \mathrm{O}_{2}$.

and reassembly process might occur after the formation of $\mu$-oxo$\mu$-peroxo species $\mathbf{S}$. We envisioned that the real active species involved in the catalytic cycle might be the disassembled monomeric peroxo $\mathrm{Ti}$ (salalen) complex ${ }^{57}$.

Asymmetric oxygenation of racemic indolines with various kinds of $\mathrm{C}_{5}$-substituents $(\mathrm{X})$ on indoline arene were performed and the reaction rates were dependent on the electronic effects of the substituents (see the Supplementary Information for details $)^{58,59}$. The Hammett plot $\left(\log \left(k_{\mathrm{X}} / k_{\mathrm{H}}\right)\right.$ versus $\left.\sigma\right)$ for the competitive oxidation of $1 \mathrm{a}$ and respective variants was exhibited in Fig. 6D. The observed plot displayed linear correlation with a $\rho$ value of $-1.347\left(R^{2}=0.99\right)$. Good linearity suggests that the oxidation proceeds through a single mechanism. The negative value of $\rho$ indicates a positive charge build-up on nitrogen in the transition state ${ }^{60}$. The use of Hammett parameter $\sigma^{+}$gave a relatively poorer correlation $\left(R^{2}=0.97\right.$, see the Supplementary Information for details). These data are consistent with a concerted mechanism, in which an electrophilic active oxygen species might be directly attacked by a nucleophilic nitrogen 61 .

Based on the above studies and literature survey, a plausible mechanistic pathway for asymmetric oxygenation of racemic indolines was suggested (Fig. 8). Treating di- $\mu$-oxo titanium(salalen) $\mathbf{C 6}$ with hydrogen peroxide gave $\mu$-oxo- $\mu$-peroxo species $\mathbf{S}$ which is the incubation period for the oxygenation process. In the presence of hydrogen peroxide, relatively stable $\mathbf{S}$ underwent a disassembly process providing monomeric peroxo Ti(salalen) complex 14, which was proposed to be the real active species involved in the catalytic cycle ${ }^{62,63}$. The asymmetric nucleophilic attack of the nitrogen of indoline rac-1a onto electrophilic oxygen of chiral complex 14 through 15 generated complex 16. 16 


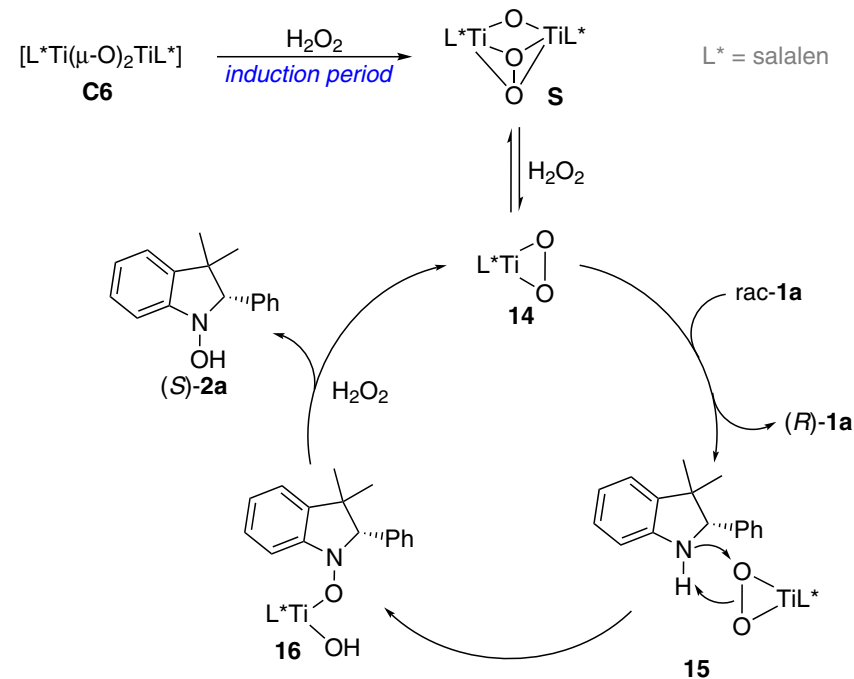

Fig. 8 Proposed mechanistic pathway. The possible reaction pathway based on our studies and the previous literatures.
TS1

(S)-1a,favored

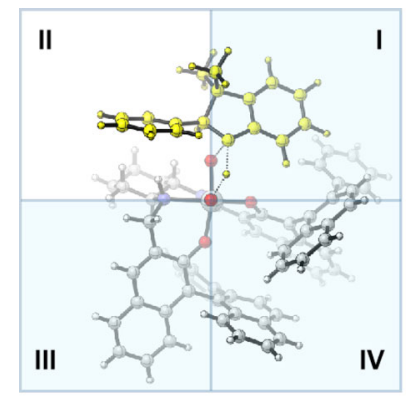

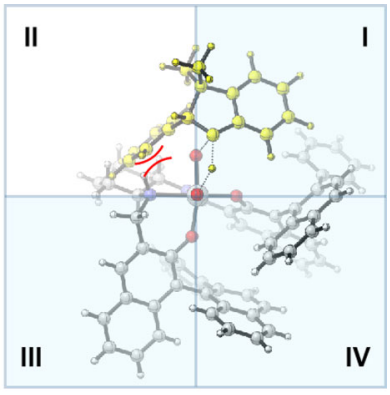

TS2
$(R)$-1a,disfavored

Fig. 9 Proposed transition state models. The transition state TS1 for ( $S$ )-1a is favored. The transition state TS2 for $(R)-\mathbf{1 a}$ is disfavored.

reacted with hydrogen peroxide providing hydroxylamine $\mathbf{2 a}$ together with $\mathbf{1 4}$ for the catalytic cycle. According to the absolute configuration of recovered indolines, we envisioned that amine $(S)$-1a was oxidized more preferentially than $(R)-\mathbf{1 a}$, and therefore unreacted $(R)$-1a was isolated with high enantioselectivity.

The stereochemical induction model was suggested in Fig. 9. The structure of monomeric peroxo Ti(salalen) complex $\mathbf{1 4}$ is proposed based on the crystal structure of di- $\mu$-oxo titanium (salalen) $\mathbf{C 6}^{64,63}$. The quadrant diagrams elaborate the origins of the chiral recognition. The steric repulsion between two $(R)$ binaphthyl unites and indoline la prevents the nucleophilic attack of the nitrogen from the third and fourth quadrants. In addition, locating the less sterically demanding phenyl moiety of indoline skeleton in the first quadrant is preferred to avoid the steric repulsion between the (R)-binaphthyl unite and the $a$ substituent of 1a. The transition state TS2 for $(R)$-1a has obvious steric repulsion between the $\alpha$-phenyl substituent of indoline with the cyclohexane moiety of salalen ligand. Such steric repulsion is absent in the transition state TS1 for (S)-1a. Therefore, (S)-1a was oxidized more preferentially than $(R)-\mathbf{1 a}$, and unreacted $(R)-\mathbf{1 a}$ was recovered with high enantioselectivity.

In summary, an oxidative KR of secondary amines based on $\mathrm{N}-\mathrm{O}$ bond formation is reported. The practical titanium(salalen) catalyzed asymmetric oxygenation with environmentally benign hydrogen peroxide as oxidant is applicable to a range of indolines with multiple stereocenters and diverse substituent patterns in high efficiency with efficient chemoselectivity and enantiodiscrimination. Late-stage asymmetric oxygenation of bioactive molecules that are otherwise difficult to synthesize was further explored. The KR of secondary amines based on $\mathrm{N}-\mathrm{O}$ bond formation described herein represents an advance in the field of asymmetric oxidation.

\section{Methods \\ General procedure. To a solution of racemic indoline $(0.1 \mathrm{mmol}, 1.0 \mathrm{eq})$ in $\mathrm{CHCl}_{3}$ $(1.0 \mathrm{~mL})$ was added $30 \%$ aqueous hydrogen peroxide $(0.1 \mathrm{mmol}, 10 \mu \mathrm{L}, 1.0 \mathrm{eq})$ and C6 (0.001 mmol, $1.8 \mathrm{mg}, 1 \mathrm{mmol} \%)$ at room temperature. The reaction was vig- orously stirred for $4-12 \mathrm{~h}$. Then the mixture was diluted with $\mathrm{CH}_{2} \mathrm{Cl}_{2}(20 \mathrm{~mL})$, washed with water $(10 \mathrm{~mL})$, dried over $\mathrm{MgSO}_{4}$, filtered, and concentrated. The residue was purified by silica gel chromatography (EtOAc/petroleum ether) to give the desired product.}

\section{Data availability}

The authors declare that the data supporting the findings of this study are available within the article and its Supplementary Information files. Extra data are available from the corresponding author upon request.

Received: 3 December 2020; Accepted: 12 March 2021; Published online: 04 May 2021

\section{References}

1. Vitaku, E., Smith, D. T. \& Njardarson, J. T. Analysis of the structural diversity, substitution patterns, and frequency of nitrogen heterocycles among U.S. FDA approved pharmaceuticals. J. Med. Chem. 57, 10257-10274 (2014).

2. Keith, J. M., Larrow, J. F. \& Jacobsen, E. N. Practical considerations in kinetic resolution reactions. Adv. Synth. Catal. 343, 5-26 (2001).

3. Breuer, M. et al. Industrial methods for the production of optically active intermediates. Angew. Chem. Int. Ed. 43, 788-824 (2004).

4. Vedejs, E. \& Jure, M. Efficiency in nonenzymatic kinetic resolution. Angew. Chem. Int. Ed. 44, 3974-4001 (2005).

5. Pellissier, H. Catalytic non-enzymatic kinetic resolution. Adv. Synth. Catal. 353, 1613-1666 (2011).

6. Müller, C. E. \& Schreiner, P. R. Organocatalytic enantioselective acyl transfer onto racemic as well as meso alcohols, amines, and thiols. Angew. Chem. Int. Ed. 50, 6012-6042 (2011).

7. Kranov, V. P., Gruzdev, D. A. \& Levit, G. L. Nonenzymatic acylative kinetic resolution of racemic amines and related compounds. Eur. J. Org. Chem. 2012, 1471-1493 (2012)

8. Kreituss, I. \& Bode, J. W. Catalytic kinetic resolution of saturated $N$ heterocycles by enantioselective amidation with chiral hydroxamic acids. Acc. Chem. Res. 49, 2807-2821 (2016)

9. Lackner, A. D., Samant, A. V. \& Toste, F. D. Single-operation deracemization of $3 \mathrm{H}$-indolines and tetrahydroquinolines enabled by phase separation. J. Am. Chem. Soc. 135, 14090-14093 (2013).

10. Ji, Y., Shi, L., Chen, M.-W., Feng, G.-S. \& Zhou, Y.-G. Concise redox deracemization of secondary and tertiary amines with a tetrahydroisoquinoline core via a nonenzymatic process. J. Am. Chem. Soc. 137, 10496-10499 (2015)

11. Zhang, L. et al. Catalytic asymmetric synthesis of $\beta, \gamma$-alkynyl $\alpha$-amino esters via chemo- and enantioselective transfer hydrogenation. Chin. J. Org. Chem. 40, 2904-2911 (2020).

12. Arp, F. O. \& Fu, G. C. Kinetic resolutions of indolines by a nonenzymatic acylation catalyst. J. Am. Chem. Soc. 128, 14264-14265 (2006).

13. Hou, X. L. \& Zheng, B. H. Kinetic resolution of indolines by Pd-catalyzed asymmetric allylic amination. Org. Lett. 11, 1789-1791 (2009).

14. Binanzer, M., Hsieh, S. Y. \& Bode, J. W. Catalytic kinetic resolution of cyclic secondary amines. J. Am. Chem. Soc. 133, 19698-19701 (2011).

15. Kreituss, I., Murakami, Y., Binanzer, M. \& Bode, J. W. Kinetic resolution of nitrogen heterocycles with a reusable polymer-supported reagent. Angew. Chem. Int. Ed. 51, 10660-10663 (2012).

16. Wanner, B., Kreituss, I., Gutierrez, O., Kozlowski, M. C. \& Bode, J. W. Catalytic kinetic resolution of disubstituted piperidines by enantioselective acylation: synthetic utility and mechanistic insights. J. Am. Chem. Soc. 137, 11491-11497 (2015)

17. Kreituss, I. et al. A robust, recyclable resin for decagram scale resolution of ( \pm -mefloquine and other chiral $N$-heterocycles. Angew. Chem. Int. Ed. 55, 1553-1556 (2016). 
18. Murray, J. I. et al. Kinetic resolution of 2-substituted indolines by $N$ sulfonylation using an atropisomeric 4-DMAP- $N$-oxide organocatalyst. Angew. Chem. Int. Ed. 56, 5760-5764 (2017).

19. Sheldon, R. A. \& Kochi, J. K. Metal Catalyzed Oxidations of Organic Compounds (Academic Press, 1984).

20. Schlecht, M. F. in Comprehensive Organic Synthesis Vol. 7 (eds Trost, B. M., Fleming, I. \& Ley, S. V.) (Oxford, 1991).

21. Bäckvall, J.-E. Modern Oxidation Methods (Wiley-VCH, 2004).

22. Beller, M. The current status and future trends in oxidation chemistry. $A d v$. Synth. Catal. 346, 107-108 (2004).

23. Stahl, S. S. Palladium oxidase catalysis: selective oxidation of organic chemicals by direct dioxygen-coupled turnover. Angew. Chem. Int. Ed. 43, 3400-3420 (2004).

24. Kolb, H. C., VanNieuwenhze, M. S. \& Sharpless, K. B. Catalytic asymmetric dihydroxylation. Chem. Rev. 94, 2483-2547 (1994).

25. Katsuki, T. Catalytic asymmetric oxidations using optically active (salen) manganese(III) complexes as catalysts. Coord. Chem. Rev. 140, 189-214 (1995).

26. Larrow, J. F. \& Jacobsen, E. N. Asymmetric processes catalyzed by chiral (salen)metal complexes. Top. Organomet. Chem. 6, 123-152 (2004).

27. Schultz, M. J. \& Sigman, M. S. Recent advances in homogeneous transition metal-catalyzed aerobic alcohol oxidations. Tetrahedron 62, 8227-8241 (2006).

28. Wong, O. A. \& Shi, Y. Organocatalytic oxidation. Asymmetric epoxidation of olefins catalyzed by chiral ketones and iminium salts. Chem. Rev. 108, 3958-3987 (2008).

29. Che, C.-M. \& Huang, J.-S. Metalloporphyrin-based oxidation systems: from biomimetic reactions to application in organic synthesis. Chem. Commun. 2009, 3996-4015 (2009).

30. Faveri, G. D., Ilyashenko, G. \& Watkinson, M. Recent advances in catalytic asymmetric epoxidation using the environmentally benign oxidant hydrogen peroxide and its derivatives. Chem. Soc. Rev. 40, 1722-1760 (2011).

31. Srour, H., Maux, P. L., Chevance, S. \& Simonneaux, G. Metal-catalyzed asymmetric sulfoxidation, epoxidation and hydroxylation by hydrogen peroxide. Coord. Chem. Rev. 257, 3030-3050 (2013).

32. Bryliakov, K. P. Catalytic asymmetric oxygenations with the environmentally benign oxidants $\mathrm{H}_{2} \mathrm{O}_{2}$ and $\mathrm{O}_{2}$. Chem. Rev. 117, 11406-11459 (2017).

33. Milan, M., Bietti, M. \& Costas, M. Enantioselective aliphatic C-H bond oxidation catalyzed by bioinspired complexes. Chem. Commun. 54, 9559-9570 (2018).

34. Sun, S., Ma, Y., Liu, Z. \& Liu, L. Oxidative kinetic resolution of cyclic benzylic ethers. Angew. Chem. Int. Ed. 60, 176-180 (2021).

35. Miyano, S., Lu, L. D. L., Viti, S. M. \& Sharpless, K. B. Kinetic resolution of racemic $\beta$-hydroxy amines by enantioselective $\mathrm{N}$-oxide formation. J. $\mathrm{Org}$. Chem. 48, 3608-3611 (1983).

36. Bhadra, S. \& Yamamoto, H. Catalytic asymmetric synthesis of N-chiral amine oxides. Angew. Chem. Int. Ed. 55, 13043-13046 (2016)

37. Saito, K., Shibata, Y., Yamanaka, M. \& Akiyama, T. Chiral phosphoric acidcatalyzed oxidative kinetic resolution of indolines based on transfer hydrogenation to imines. J. Am. Chem. Soc. 135, 11740-11743 (2013).

38. Saito, K. \& Akiyama, T. Chiral phosphoric acid catalyzed kinetic resolution of indolines based on a self-redox reaction. Angew. Chem. Int. Ed. 55, 3148 (2016).

39. Lu, R., Cao, L., Guan, H. \& Liu, L. Iron-catalyzed aerobic dehydrogenative kinetic resolution of cyclic secondary amines. J. Am. Chem. Soc. 141, 6318-6324 (2019).

40. Murahashi, S.-I. \& Imada, Y. Synthesis and transformations of nitrones for organic synthesis. Chem. Rev. 119, 4684-4716 (2019)

41. Bryliakov, K. Environmentally Sustainable Catalytic Asymmetric Oxidations (CRC Press, 2014).

42. Romano, C., Jia, M., Monari, M., Manoni, E. \& Bandini, M. Metal-free enantioselective electrophilic activation of allenamides: stereoselective dearomatization of indoles. Angew. Chem. Int. Ed. 53, 13854-13857 (2014).

43. Zhao, X. et al. Asymmetric dearomatization of indoles through a Michael/ Friedel-Crafts-type cascade to construct polycyclic spiroindolines. Angew. Chem. Int. Ed. 54, 4032-4035 (2015).

44. Sharma, K. et al. Cation-controlled enantioselective and diastereoselective synthesis of indolines: an autoinductive phase-transfer initiated 5-endo-trig process. J. Am. Chem. Soc. 137, 13414-13424 (2015).

45. Zhuo, C.-X., Zhou, Y., Cheng, Q., Huang, L. \& You, S.-L. Enantioselective construction of spiroindolines with three contiguous stereogenic centers and chiral tryptamine derivatives via reactive spiroindolenine intermediates. Angew. Chem. Int. Ed. 54, 14146-14149 (2015).

46. Yang, Z., Chen, F., He, Y., Yang, N. \& Fan, Q.-H. Highly enantioselective synthesis of indolines: asymmetric hydrogenation at ambient temperature and pressure with cationic ruthenium diamine catalysts. Angew. Chem. Int. Ed. 55, 13863-13866 (2016).

47. Niemeyer, Z. L. et al. Parameterization of acyclic diaminocarbene ligands applied to a gold(I)-catalyzed enantioselective tandem rearrangement/ cyclization. J. Am. Chem. Soc. 139, 12943-12946 (2017).
48. Büchi, G., Matsumoto, K. E. \& Nishimura, H. The total synthesis of ( \pm )-vindorosine. J. Am. Chem. Soc. 93, 3299-3301 (1971).

49. Feldman, P. L. \& Rapoport, H. Synthesis of (-)-vindoline. J. Am. Chem. Soc. 109, 1603-1604 (1987).

50. Ishikawa, H., Elliott, G. I., Velcicky, J., Choi, Y. \& Boger, D. L. Total synthesis of (-)- and ent-(+)-vindoline and related alkaloids. J. Am. Chem. Soc. 128 , 10596-10612 (2006).

51. Yamada, F., Kawanishi, A., Tomita, A. \& Somei, M. The first preparation of the unstable 1-hydroxy-2,3-dimethylindole, and structural determination of its air-oxidized product, 3-hydroxy-2,3-dimethyl-3H-indole $\mathrm{N}$-oxide. Arkivoc 8, 102-111 (2003).

52. Gerken, P. A. et al. Discovery of a highly selective cell-active inhibitor of the histone lysine demethylases KDM2/7. Angew. Chem. Int. Ed. 56, 15555-15559 (2017).

53. Panknin, O. et al. Spiro[indolin-3,4,-piperidine] derivatives as gnrh receptor anatagonists. (PCT Int. Appl. WO 2015091315A1, 2015).

54. Ouchot, C. et al. Nonlinear effects in asymmetric synthesis. Examples in asymmetric oxidations and aldolization reactions. J. Am. Chem. Soc. 108, 2353-2357 (1986).

55. Johnson, D. W. Jr. \& Singleton, D. A. Nonlinear effects in kinetic resolutions. J. Am. Chem. Soc. 121, 9307-9312 (1999).

56. Berkessel, A., Günther, T., Wang, Q. \& Neudörfl, J.-M. Titanium salalen catalysts based on cis-1,2-diaminocyclohexane: enantioselective epoxidation of terminal non conjugated olefins with $\mathrm{H}_{2} \mathrm{O}_{2}$. Angew. Chem. Int. Ed. 52, 8467-8471 (2013)

57. Sawada, Y. et al. Titanium-salan-catalyzed asymmetric epoxidation with aqueous hydrogen peroxide as the oxidant. Angew. Chem. Int. Ed. 45, 3478-3480 (2006)

58. Hammett, L. P. Physical Organic Chemistry (McGraw-Hill Book Co., 1970).

59. Hammett, L. P. Some relations between reaction rates and equilibrium constants. Chem. Rev. 17, 125-136 (1935).

60. Park, M. J., Lee, J., Suh, Y., Kim, J. \& Nam, W. Reactivities of mononuclear non-heme iron intermediates including evidence that iron(III)-hydroperoxo species is a sluggish oxidant. J. Am. Chem. Soc. 128, 2630-2634 (2006).

61. Duboc-Toia, C. et al. Enantioselective sulfoxidation as a probe for a metalbased mechanism in $\mathrm{H}_{2} \mathrm{O}_{2}$-dependent oxidations catalyzed by a diiron complex. Inorg. Chem. 38, 1261-1268 (1999).

62. Dakanali, M. et al. A new dinuclear Ti(IV)-peroxo-citrate complex from aqueous solutions. Synthetic, structural, and spectroscopic studies in relevance to aqueous titanium(IV)-peroxo-citrate speciation. Inorg. Chem. 42, 4632-4639 (2003)

63. Panda, M. K., Shaikh, M. M. \& Ghosh, P. Controlled oxidation of organic sulfides to sulfoxides under ambient conditions by a series of titanium isopropoxide complexes using environmentally benign $\mathrm{H}_{2} \mathrm{O}_{2}$ as an oxidant. Dalton Trans. 39, 2428-2440 (2010).

64. Matsumoto, K., Sawada, Y., Saito, B., Sakai, K. \& Katsuki, T. Construction of pseudo-heterochiral and homochiral di- $\mu$-oxotitanium(Schiff base) dimers and enantioselective epoxidation using aqueous hydrogen peroxide. Angew. Chem. Int. Ed. 44, 4935-4939 (2005).

\section{Acknowledgements}

Financial supports were provided by the National Science Foundation of China (21971148, 21722204), Shenzhen Special Funds (JCYJ20190807093805572), and Youth Interdiscipline Innovative Research Group of Shandong University (2020QNQT009).

\section{Author contributions}

G.W. conducted the asymmetric oxygenation experiments and mechanistic studies; R.L. and C.H. prepared the substrates; L.L. designed the experiments and wrote the paper.

\section{Competing interests}

The authors declare no competing interests.

\section{Additional information}

Supplementary information The online version contains supplementary material available at https://doi.org/10.1038/s41467-021-22658-3.

Correspondence and requests for materials should be addressed to L.L.

Peer review information Nature Communications thanks the anonymous reviewers for their contribution to the peer review of this work.

Reprints and permission information is available at http://www.nature.com/reprints

Publisher's note Springer Nature remains neutral with regard to jurisdictional claims in published maps and institutional affiliations. 
(c) (i) Open Access This article is licensed under a Creative Commons Attribution 4.0 International License, which permits use, sharing, adaptation, distribution and reproduction in any medium or format, as long as you give appropriate credit to the original author(s) and the source, provide a link to the Creative Commons license, and indicate if changes were made. The images or other third party material in this article are included in the article's Creative Commons license, unless indicated otherwise in a credit line to the material. If material is not included in the article's Creative Commons license and your intended use is not permitted by statutory regulation or exceeds the permitted use, you will need to obtain permission directly from the copyright holder. To view a copy of this license, visit http://creativecommons.org/ licenses/by/4.0/.

(C) The Author(s) 2021 